\title{
Short communication: Lethal mutations in Vorderwald cattle through Montbéliarde incrossings
}

\author{
S. Reinartz and O. Distl* (D) \\ Institute for Animal Breeding and Genetics, University of Veterinary Medicine Hannover, 30559 Hannover, Germany
}

\begin{abstract}
Vorderwald cattle are a dual-purpose cattle breed with high migrant contributions from Montbéliarde bulls in the recent past. Through the wide use of Montbéliarde bulls, undesirable alleles were also disseminated into the Vorderwald population. Haplotypes on bovine chromosome 19 (MH1) and 29 (MH2), supposed to harbor lethal mutations, were identified in Montbéliarde cattle. A study in French Montbéliarde cattle identified the PFAS:g.28511199C > T (rs455876205) variant as the most likely MH1 embryonic lethal mutation. The objective of the present study was to determine whether the PFAS:g.28511199C $>$ T variant was introduced into Vorderwald cattle through Montbéliarde bulls and disseminated in this population. The present study expands on previous work on the deleterious SLC37A2 variant (ss2019324563) of the MH2 locus. Herein, we traced the ss2019324563 variant back to the Montbéliarde bull, which was the most likely source for this deleterious mutation in Vorderwald cattle. We genotyped 354 Vorderwald cattle for the PFAS variant, resulting in 41 heterozygous individuals and a $\mathrm{T}$ allele frequency of 0.058 . An aborted fetus homozygous mutant for SLC37A2 from our previous study on the MH2 locus in Vorderwald cattle was wild type for the PFAS variant. Both lethal mutations were segregating independently of each other, and we found no indications of joint occurrence in a larger number of animals. Neither SLC37A2 nor PFAS double heterozygous mutants were lethal. The earliest animal with a heterozygous PFAS genotype was 1 of 5 migrant Montbéliarde bulls, and this bull was the most likely origin of the deleterious PFAS allele in Vorderwald cattle. All Vorderwald cattle under study born before introgression of this Montbéliarde bull were homozygous wild type. In addition, all 41 heterozygous Vorderwald cattle had genetic contributions
\end{abstract}

Received July 5, 2019

Accepted September 9, 2019.

*Corresponding author: ottmar.distl@tiho-hannover.de from this Montbéliarde bull, whereas in 74 Vorderwald cattle without genes from Montbéliarde bulls, the PFAS T allele was not observed. In a sample of actual German Fleckvieh the PFAS T allele could be found at a very low frequency. Our study demonstrated the introgression of lethal variants through Montbéliarde bulls into a traditional cattle breed highly adapted to harsh local conditions. These findings underline the need to screen bulls for lethal mutations before their wide use in breeding, particularly in breeds with a focus on preservation of their genetic uniqueness.

Key words: lethal mutant, Vorderwald, incrossing, phosphoribosylformylglycinamidine synthase

\section{Short Communication}

Vorderwald cattle are an important dual-purpose breed adapted to the mountainous region of the Black Forest in Baden-Württemberg, in the southwest of Germany. Their small population size makes it difficult to achieve high genetic progress in performance traits similar to that of German Fleckvieh, German Brown, or Holsteins. To compensate for the lower genetic improvement and to reduce rates of inbreeding, Holstein, Ayrshire, and Montbéliarde bulls were introduced for crossbreeding with Vorderwald cows for limited periods (Sambraus, 1994; Hartwig et al., 2014). Contributions from these sires had significant positive effects on milk performance traits in Vorderwald cattle (Hartwig et al., 2015). The largest migrant contributions came from 5 Montbéliarde bulls in the 1990s (Hartwig et al., 2014; Reinartz and Distl, 2016). In Montbéliarde cattle, 2 recessive lethal haplotypes, MH1 and MH2, have been detected (Fritz et al., 2013). Variants in sex hormone binding globulin $(\boldsymbol{S H} \boldsymbol{B} \boldsymbol{G})$ and solute carrier family 37 A2 (SLC37A2) were considered to be the responsible lethal mutations in $\mathrm{MH} 1$ and $\mathrm{MH} 2$, respectively. Migrant Montbéliarde bulls introduced the deleterious SLC37A2 mutation (MH2) into Vorderwald cattle (Reinartz and Distl, 2016). An investigation of an aborted Vorderwald fetus demonstrated the embryonic lethal effect of the SLC37A2:g.28879810C>T mutation and its wide 
dissemination in Vorderwald cattle through admixture with Montbéliarde bulls (Reinartz and Distl, 2016). The $S H B G$ locus (SHBG:g.27956790C > T, rs38377500) was ruled out as a candidate harboring a deleterious MH1 variant in Vorderwald (Reinartz and Distl, 2016) and later in Montbéliarde cattle (Michot et al., 2017). The $S H B G$ T allele frequency was 0.12 in Vorderwald cattle and was common in other cattle breeds (Reinartz and Distl, 2016). Further study of the MH1 haplotype identified a variant within phosphoribosylformylglycinamidine synthase (PFAS; PFAS:g.28511199C $>$ T, rs455876205) as the most likely candidate for embryonic lethality among French Montbéliarde (Michot et al., 2017). In Montbéliarde cattle, the MH1 haplotype was spread through the bull Boislevin and his sons. Recombination events occurring in his grandson Redon and great-grandson Rapallo allowed fine mapping of MH1 and identification of the PFAS:g.28511199C > T variant (Michot et al., 2017). This variant is located in a class I glutamine amidotransferase-like domain, causing a substitution of an arginine by a cysteine (p.R1205C). This amino acid is highly conserved within eukaryotes, displaying an important role of the PFAS gene in purine synthesis. Synthesis of DNA and RNA as well as energy supply for cells are important tasks of this gene (Henikoff, 1987; Clark, 1994; Bønsdorff et al., 2004).

The objectives of the present study were to prove whether the PFAS:g.28511199C > T variant was introgressed into Vorderwald cattle and whether migrant Montbéliarde bulls may be identified as having contributed to dissemination of this deleterious mutation. Through analysis of pedigrees with MH1 and MH2 carriers, we searched for the most likely sources of these deleterious alleles among migrant Montbéliarde bulls. In addition, we screened our data for animals carrying both deleterious MH1 and MH2 mutations. This study expands on a previous analysis among Vorderwald cattle by Reinartz and Distl (2016), on the candidate mutations $S H B G: \mathrm{g} .27956790 \mathrm{C}>\mathrm{T}$ within $\mathrm{MH} 1$ and SLC37A2:g.28879810C > T within MH2 (Fritz et al., 2013).

Sampling included 354 Vorderwald cattle, 106 German Fleckvieh, 99 German Brown, and 68 animals of the breeds Angus, Blonde d'Aquitaine, Charolais, Holstein, Limousin, and Salers. Genomic DNA was isolated from EDTA blood using standard protocols. Genotyping of the PFAS:g.28511199C > T (rs455876205) variant was performed using a mismatch PCR-RFLP and the restriction enzyme BmgBI (Supplemental Table S1; https://doi.org/10.3168/jds.2019-17213).

Polymorphism information content, heterozygosity, allele and genotype frequencies, and $\chi^{2}$ tests for
Hardy-Weinberg equilibrium were calculated using the ALLELE procedure of SAS/Genetics, version 9.4 (SAS Institute, Cary, NC). The software OPTI-MATE, version 3.88 (Schmidt and Wrede, 2006) was used to calculate the proportions of Montbéliarde and Ayrshire blood.

Allele frequency of the PFAS T allele in 354 Vorderwald cattle was 0.058. In French Montbéliarde cattle, the allele frequency was slightly higher, with an estimate of 0.067 (Michot et al., 2017). We found 41 heterozygous mutant and 313 homozygous wild type but no homozygous mutant individuals (Table 1). All 74 Vorderwald cattle without genetic contributions from Montbéliarde bulls were genotyped as homozygous wild type for the PFAS variant. All carriers of the PFAS variant had Montbéliarde blood proportions at 18.8 to $53.1 \%$, whereas Ayrshire blood proportions were at 0.2 to $2.2 \%$. Homozygous wild-type Vorderwald cattle had Ayrshire blood proportions up to 13\%. The earliest heterozygous animal was a bull born in 1986 and used in AI for Vorderwald cattle (Figure 1). This was 1 of the 5 Montbéliarde bulls (bull E, Figure 1) migrating into Vorderwald cattle in the 1990s. A French study traced the MH1 haplotype to the Montbéliarde bull Boislevin (Michot et al., 2017). Our pedigree analysis showed the maternal grandsire of Boislevin, Debout, as the most recent common ancestor to the earliest Montbéliarde bull genotyped as a PFAS carrier in the present study. The Montbéliarde bull Debout is very likely the origin for the PFAS variant transmitted via the maternal path to Montbéliarde bull E. All PFAS heterozygous Vorderwald cattle had bull $\mathrm{E}$ as an ancestor in their pedigrees, with relationship coefficients from 0.2 to $50 \%$. It was also obvious that the deleterious PFAS mutation was maintained up to the actual population.

We estimated a nonrecombinant MH1 haplotype in the PFAS heterozygous Montbéliarde bull $\mathrm{E}$ with both mutated alleles of the MH1 variants, SHBG and PFAS. All progeny of Montbéliarde bull E investigated here showed haplotypes containing both mutant alleles of $S H B G$ and PFAS on one chromosome and wild-type alleles on the other. We did not verify recombinant hap-

Table 1. Number and origin of Vorderwald cattle genotyped for the PFAS:g.28511199C > T (rs455876205) variant

\begin{tabular}{lrrr}
\hline & & \multicolumn{2}{c}{ PFAS genotype } \\
\cline { 3 - 4 } Origin of sample & $\mathrm{N}$ & $\mathrm{C} / \mathrm{T}$ & $\mathrm{C} / \mathrm{C}$ \\
\hline Experimental herd & 30 & 2 & 28 \\
Aborted fetus & 1 & 0 & 1 \\
Farms & 323 & 39 & 284 \\
Total & 354 & 41 & 313 \\
\hline
\end{tabular}




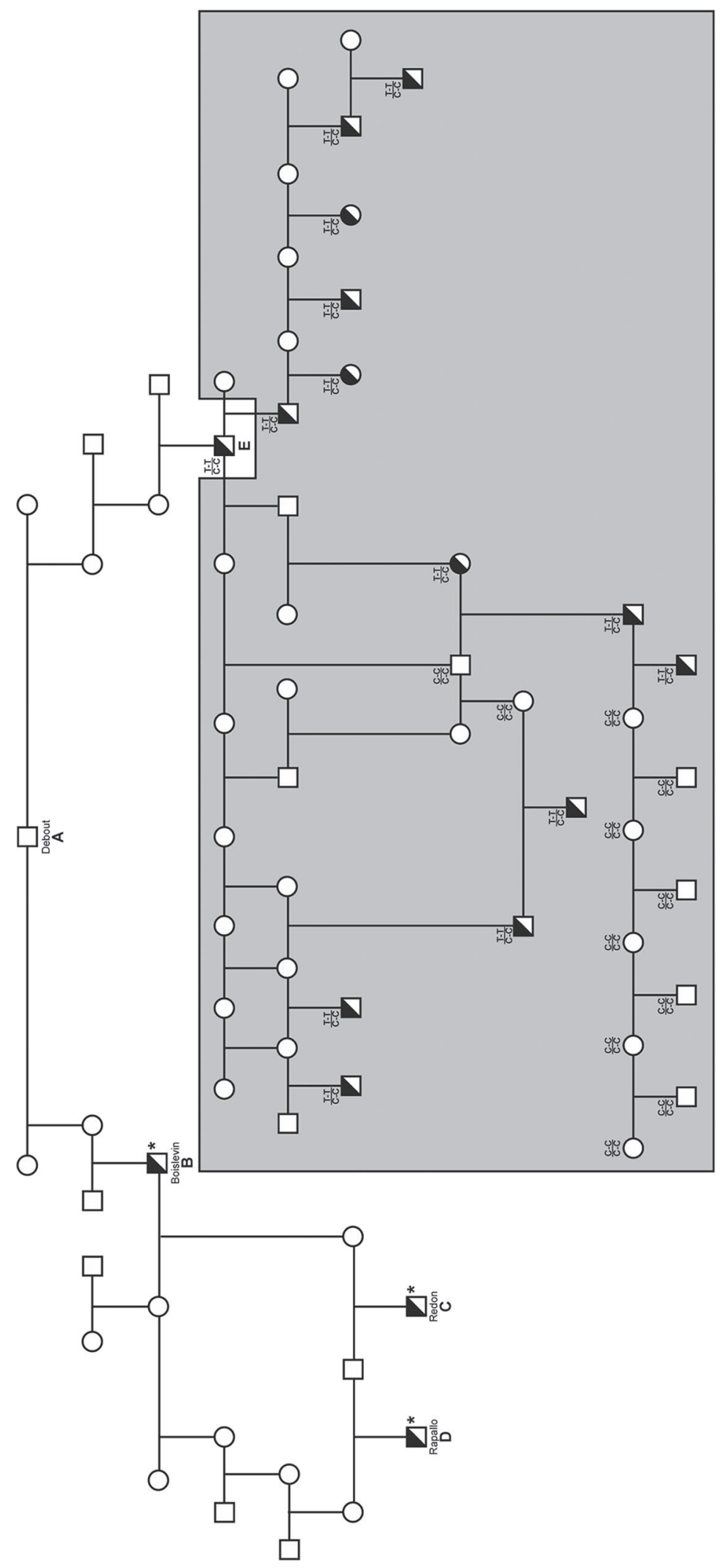

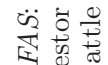

记

娄需

过责

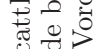

듀.

完造

范究

둼

更要

을 윰

어의

흘

웡클

过

药奉市

6009

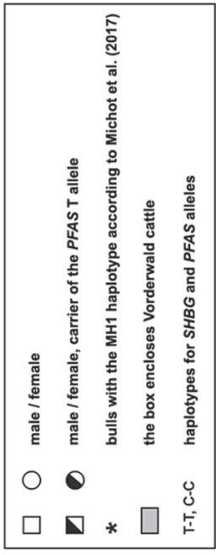

卷寻

范要

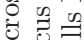

으응

궁

$\exists$

눙

न

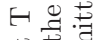

范

苋可

들 छ

is

ํㅜㅇ

을

西

ํㅣㅁ

ज证

䜦

造

은 긍

ㄷํ

考

क

5.

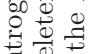

正

ษ

동

क

\&. .

50

ค 의

-

용.

00 表

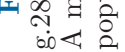




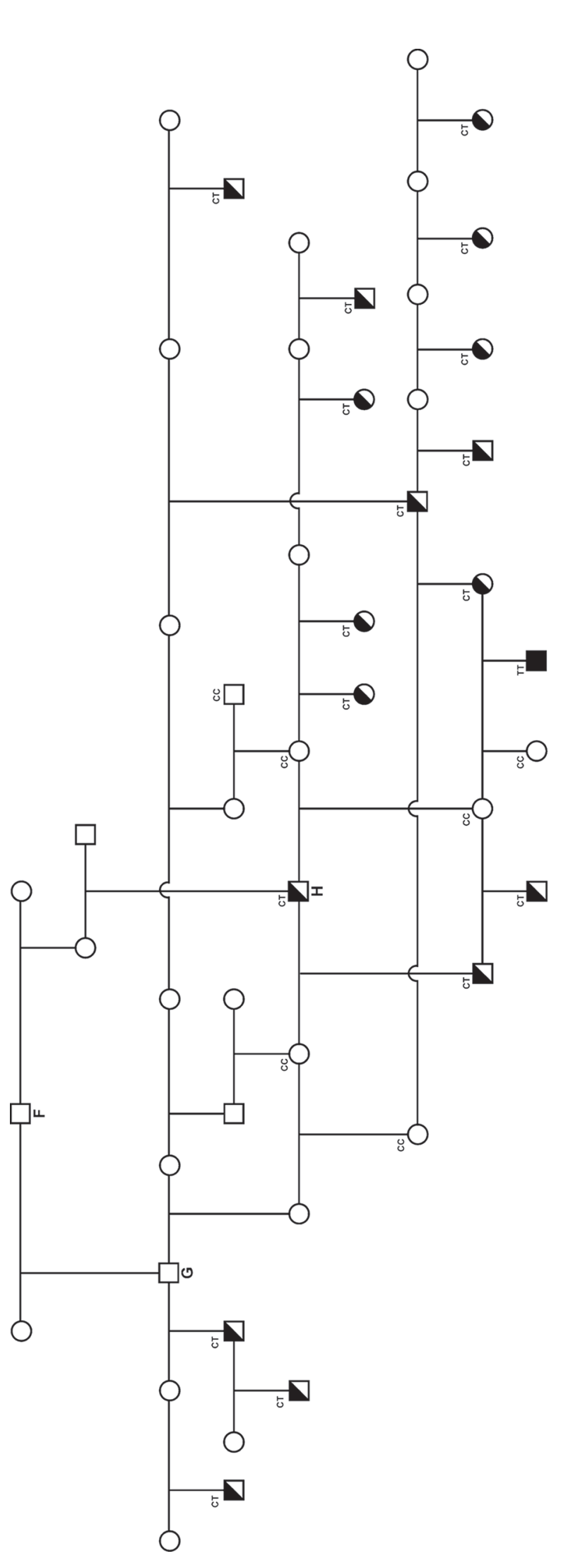

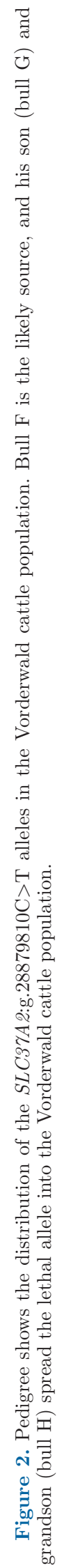


lotypes as reported by Michot et al. (2017). Vorderwald cattle with the PFAS T allele were, in all cases, also carriers of the $S H B G \mathrm{~T}$ allele. Thus, estimated haplotype frequency with both mutated alleles of $S H B G$ and $P F A S$ was identical with the allele frequency for the $P F A S$ T allele (0.058). The haplotype with the mutated $S H B G \mathrm{~T}$ allele and wild-type $P F A S \mathrm{C}$ allele had a frequency of 0.052 . All other haplotypes were wild type (0.89) for both alleles.

Among the 126 Vorderwald males sampled, we found 16 to be heterozygous, and among the 228 Vorderwald females, 29 were heterozygous. Allele frequencies in males and females were 0.064 and 0.037 , respectively. No significant deviations in genotype and allele frequencies were found between the sexes.

To validate the origin of the PFAS variant in Montbéliarde cattle, we genotyped 68 animals from 7 different cattle breeds and 99 German Brown. We did not find the PFAS T allele, indicative of an origin in Montbéliarde cattle, in any animals from these breeds. In 106 German Fleckvieh samples from the birth years 2008 to 2016, 2 bulls were heterozygous for the PFAS $\mathrm{T}$ allele. The PFAS heterozygous German Fleckvieh bulls were paternal half-siblings born in 2012 and 2015 . These 2 bulls had the same paternal grandsire (Malefiz, DE09 15079575), which sired the known PFAS carrier Mangfall (DE09 35463615), as reported by Michot et al. (2017). Possibly segregation of the PFAS T allele happened via the Fleckvieh bull Malefiz.

A previous study showed a homozygous mutant genotype of the lethal SLC37A2:g.28879810C > T mutation in an aborted Vorderwald fetus and dissemination of the mutant SLC37A2 allele through admixture with Montbéliarde (Reinartz and Distl, 2016). We searched the available pedigrees of $S L C 37 A 2 \mathrm{~T}$ allele carriers to locate the source of this SLC37A2 variant. The SLC37A2 T allele was introgressed in the Vorderwald population through another of the 5 Montbéliarde bulls (Figure 2). Here, we identified Montbéliarde bull $\mathrm{F}$ as the likely origin of the deleterious SLC37A2 T allele. A son (bull G) and a grandson (bull $\mathrm{H}$ ) of Montbéliarde bull $\mathrm{F}$ were also heterozygous and contributed to dissemination of the SLC37A2 T allele. Montbéliarde bull E was homozygous wild type for the SLC37A2 variant. Only 3 out of 344 animals were double heterozygous for both variants within SLC37A2 and PFAS (Table 2). The aborted Vorderwald fetus was homozygous mutant for SLC37A2 and homozygous wild type for PFAS, as were his parents and grandparents. With an estimate of 0.0424, the SLC37A2 T allele frequency was lower than that of the PFAS T allele frequency.

In agreement with Michot et al. (2017), we found no homozygous PFAS mutant individuals, and, thus,
Table 2. Joint distribution of the PFAS:g.28511199C $>\mathrm{T}$ and SLC37A2:g.28879810C > T genotypes in 344 Vorderwald cattle

\begin{tabular}{lcccc}
\hline Item & PFAS: C/C & PFAS: C/T & PFAS: $\mathrm{T} / \mathrm{T}$ & Total \\
\hline SLC37A2: C/C & 278 & 38 & 0 & 316 \\
SLC37A2: C/T & 24 & 3 & 0 & 27 \\
SLC37A2: T/T & 1 & 0 & 0 & 1 \\
Total & 303 & 41 & 0 & 344 \\
\hline
\end{tabular}

our data may support a deleterious effect of the PFAS: g. $28511199 \mathrm{C}>\mathrm{T}$ variant. Pedigree analysis and genotyping of a large number of Vorderwald cattle with migrant contributions from Montbéliarde bulls showed introgression of the deleterious mutations in SLC37A2 and PFAS through 1 Montbéliarde bull each. Dissemination of the deleterious PFAS variant in Vorderwald cattle, with an actual population size of approximately 12,460 cows, reached a high PFAS T allele frequency similar to that of the French Montbéliarde population. Heterozygosity for both variants, SLC37A2 and PFAS, was not lethal. In conclusion, genotyping of the deleterious SLC37A2 and PFAS variants must be initiated among Vorderwald cattle to avoid further dissemination of these variants. A compulsory PFAS screening program also must be set up for Fleckvieh bulls. All bulls intended for breeding must be homozygous wild type for both deleterious variants, according to German animal welfare legislation.

\section{ACKNOWLEDGMENTS}

We thank all cattle breeders for the providing samples from their animals and for sharing pedigree data with us. For their support in collecting samples and providing pedigree data, we particularly thank F. Maus and Michaela Reinhardt, Landratsamt Schwarzwald-BaarKreis, Sachgebiet Tierzucht, Germany. We also thank AI centers in Bavaria and Baden-Württemberg for their readiness to donate semen samples for this study.

\section{REFERENCES}

Bønsdorff, T., M. Gautier, W. Farstad, K. Rønningen, F. Lingaas, and I. Olsaker. 2004. Mapping of the bovine genes of the de novo AMP synthesis pathway 1. Anim. Genet. 35:438-444.

Clark, D. V. 1994. Molecular and genetic analyses of Drosophila Prat, which encodes the first enzyme of de novo purine biosynthesis. Genetics 136:547-557.

Fritz, S., A. Capitan, A. Djari, S. C. Rodriguez, A. Barbat, A. Baur, C. Grohs, B. Weiss, M. Boussaha, D. Esquerré, C. Klopp, D. Rocha, and D. Boichard. 2013. Detection of haplotypes associated with prenatal death in dairy cattle and identification of deleterious mutations in GART, SHBG and SLC37A2. PLoS One 8:e65550.

Hartwig, S., R. Wellmann, R. Emmerling, H. Hamann, and J. Bennewitz. 2015. Importance of introgression for milk traits in the German Vorderwald and Hinterwald cattle. J. Dairy Sci. 98:20332038 . 
Hartwig, S., R. Wellmann, H. Hamann, and J. Bennewitz. 2014. The contribution of migrant breeds to the genetic gain of beef traits of German Vorderwald and Hinterwald cattle. J. Anim. Breed. Genet. 131:496-503.

Henikoff, S. 1987. Multifunctional polypeptides for purine de novo synthesis. BioEssays 6:8-13.

Michot, P., S. Fritz, A. Barbat, M. Boussaha, M.-C. Deloche, C. Grohs, C. Hoze, L. Le Berre, D. Le Bourhis, O. Desnoes, P. Salvetti, L. Schibler, D. Boichard, and A. Capitan. 2017. A missense mutation in PFAS (phosphoribosylformylglycinamidine synthase) is likely causal for embryonic lethality associated with the MH1 haplotype in Montbéliarde dairy cattle. J. Dairy Sci. 100:8176-8187.

Reinartz, S., and O. Distl. 2016. Validation of deleterious mutations in Vorderwald cattle. PLoS One 11:e0160013.
Sambraus, H. 1994. Gefährdete Nutztierrassen. Ihre Zuchtgeschichte, Nutzung und Bewahrung. Ulmer, Stuttgart, Germany.

Schmidt, T., and J. Wrede. 2006. OPTI-MATE Version 3.88: Software for the management of endangered populations. Hannover, Institute for Animal Breeding and Genetics, University of Veterinary Medicine Hannover, Germany.

\section{ORCIDS}

O. Distl ๑ https://orcid.org/0000-0002-3516-836X 